\title{
Manual Liquid Based Cytology in Diagnosis of Gynecologic Pathology
}

\author{
Nandini N. Manoli ${ }^{1}$, Nandish S. Manoli ${ }^{2}$, Lopamudra Kakoti ${ }^{1}$, Akshata Kamath ${ }^{1}$, Shweta Kulkarni ${ }^{1}$ \\ ${ }^{1}$ Dept of Pathology, Jagadguru Shri Shivarathreswara Medical College, Jagadguru Shri Shivarathreswara University, Mysore Karnataka, \\ India \\ ${ }^{2}$ Dept of OBG, JSS Medical College, JSS University, Mysore Karnataka, India
}

Email address:

nandinimanoli65@gmail.com (N. N. Manoli),nanda_dr05@yahoo.com (N. N. Manoli)

\section{To cite this article:}

Nandini N. Manoli, Nandish S. Manoli, Lopamudra Kakoti, Akshata Kamath, Shweta Kulkarni. Manual Liquid Based Cytology in Diagnosis of Gynecologic Pathology. Cancer Research Journal. Vol. 4, No. 4, 2016, pp. 58-68. doi: 10.11648/j.crj.20160404.11

Received: February 18, 2016; Accepted: March 21, 2016; Published: June 13, 2016

\begin{abstract}
Abnormal uterine bleeding (AUB) is a commonly encountered complaint in gynecology department. Endometrial cancer is the fourth most common malignancy in women and the most frequent gynecological cancer in developed countries. With 5,28, 000 new cases every year, cervical cancer is the fourth most common cancer affecting women worldwide, after breast, colorectal, and lung cancers. Though the cytological examination has been the mainstay for early detection of cervical cancer, and found to be useful in detection of endometrial cancer, its widespread use has not been possible in the developing countries due to paucity of resources, man power and other facilities Its sensitivity reduces to less than $50 \%$ when there is presence of obscuring blood, inflammation or thick areas of overlapping epithelial cells. Manual Liquid Based Cytology (MLBC) is a cost effective technique that enables cells to be suspended in a monolayer and thus improve detection of precursor lesions and specimen adequacy. The residual sample can be used for other tests like Cell block and immunocytochemistry. Objectives: 1. To improve the diagnosis of gynecological cancers by a method called as Manual Liquid Based Cytology (MLBC). 2. To study a cost effective method of studying both endometrial and cervical cancer with help of ancillary techniques like cellblock, immunocytochemistry 3To compare the findings between conventional pap smear (CPS) and MLBC in detection of gynecological conditions of endometrium and cervix. Methodology: Samples were collected using Ayres spatula by split sample technique from transformation zone of cervix which included outpatients of gynecology dept. The women were aged between 20-60 years, 82 cases with bleeding history were taken to study endometrial pathology, while 100 cases of white discharge per vagina were selected to study the cervix. 60 cases were later subjected to ancillary studies like cellblock with Immunocytochemistry. Histopathological correlation was done for cases wherever possible. Results: The study on endometruim showed MLBC is more sensitive and specific than CPS in diagnosis of malignant lesions. The contingency coefficient for LBC/Histopathology V/s CPS/Histopathology was $0.572 \mathrm{~V} / \mathrm{s} 0.556$. It was observed for cervical lesion that increased detection rate was $150 \%$ for low grade intraepithelial lesion. The Positive predictive value for diagnosing neoplastic lesions on cell blocks was 75\%, while Concordance Rate of CB/Histopathology Vs CPS/Histopathology was 74\% vs. 54\%. Conclusion: MLBC is a cost effective method for detections of cancerous lesions of endometruim and cervix.
\end{abstract}

Keywords: Manual Liquid Based Cytology, Endometrium, Cervix

\section{Introduction}

Endometrial carcinoma (EC) is the commonest malignancy of the female genital tract in the USA and Europe, accounting for nearly $50 \%$ of all new diagnoses of gynecological cancer $[1,2,3]$. The incidence of EC increased from 13.5 to 20.3 per 100, 000 between 1993 and 2010 in the UK, [4] and the incidence and mortality have been reported to have increased by $1.1 \%$ and $0.3 \%$, respectively, annually during the same period of time in the USA [5]. The incidence of EC is also increasing in Japan, even in younger age groups, [6] where it has become more frequent each year over a period of 30 years, and as a proportion of all uterine carcinoma rose from $10 \%$ in 1983 to $45 \%$ in 2004 [7]. The main risk factors for EC are obesity, diabetes, estrogen use, tamoxifen treatment 
polycystic ovarian syndrome (PCOS), a history of infertility, alcohol abuse and antidepressant agents [8, 9, 10, 11]. Many of these factors are tightly linked to current lifestyles in developed countries. A small but significant percentage (about 2-3\%) of EC is attributable to Lynch syndrome, a hereditary cancer predisposition syndrome which significantly increases the risk of colorectal, endometrial and other cancers. [1, 2] Fig-1

With 528, 000 new cases every year, cervical cancer is the fourth most common cancer affecting women worldwide, after breast, colorectal, and lung cancers; it is most notable in the lower-resource countries of sub-Saharan Africa. It is also the fourth most common cause of cancer death (266 000 deaths in 2012) in women worldwide. [12] Almost 70\% of the global burden falls in areas with lower levels of development, and more than one fifth of all new cases are diagnosed in India. Fig-2

\section{Endometrial and Uterine Cancer Incidence, by Race/Ethnicity and Age, 2000-2005}

Source II.9: National Cancer Institute, Surveillanee, Epidemiology, and End Results (SEER) Program

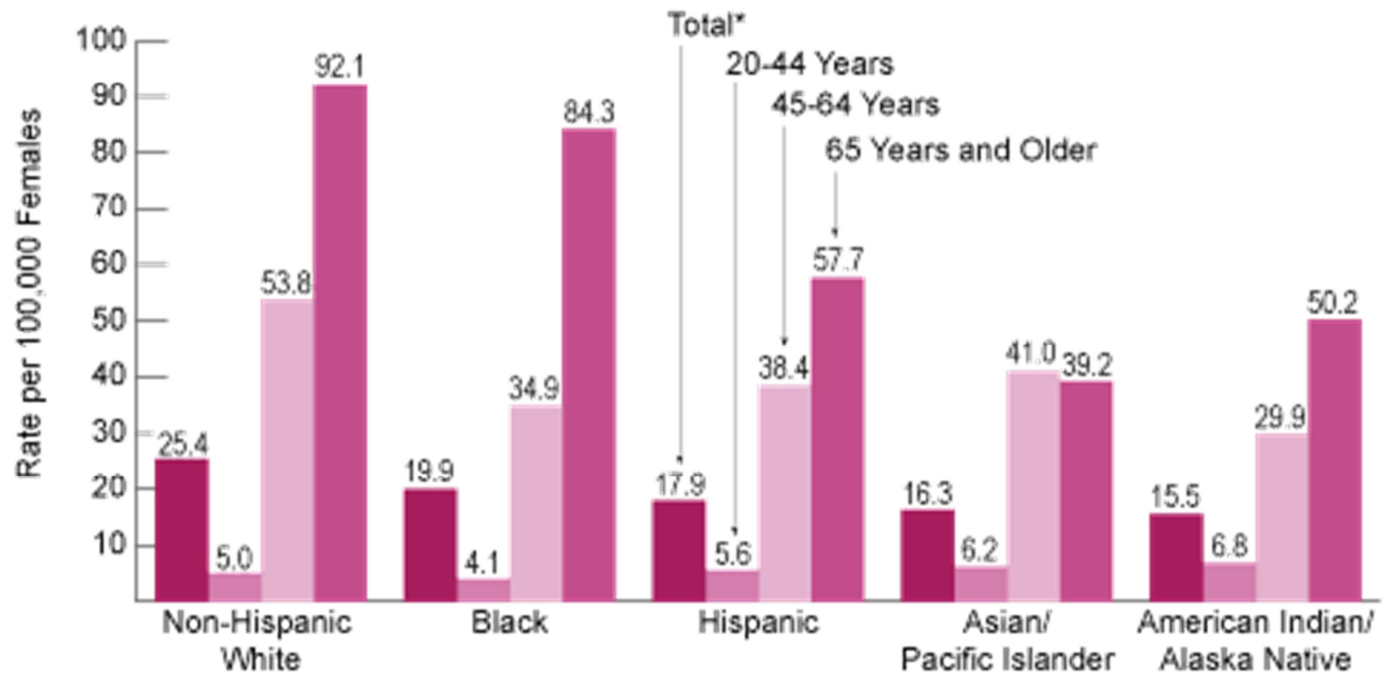

*Totals include fermales of all ages. "May include Hispanics

Fig. 1. Graph showing the incidence of endometrial carcinoma with age and ethnicity.

Estimated Incidence and Mortality Rates of Cervical Cancers - GLOBOCAN Cancer Fact Sheets

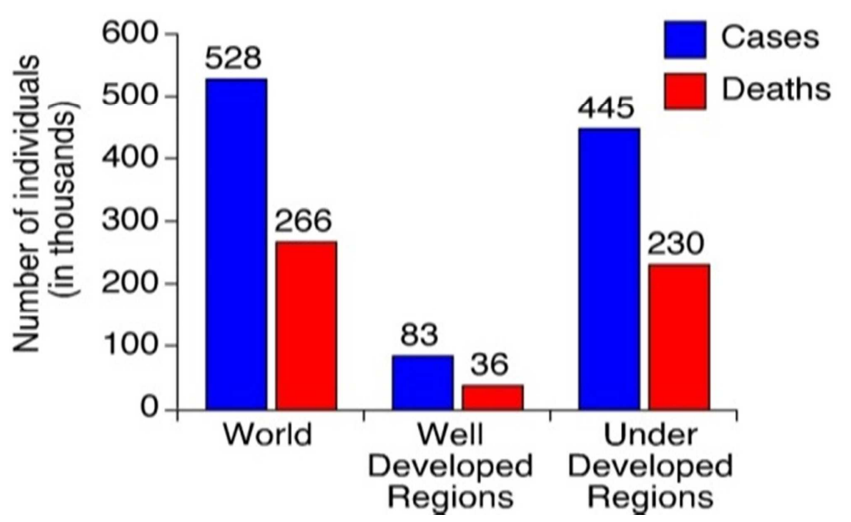

Fig. 2. Worldwide incidence of cervical cancer.

The main focus is on the secondary prevention of cervical cancer through early detection, a focus point of National Cancer Control Programme revised in 1985 [13]. Though the cytological examination has been the mainstay for early detection of cervical cancer, its widespread use has not been possible in the developing countries due to paucity of resources, man power and other facilities. Moreover, although Conventional Pap Smears (CPS) screening leads to reduction in the rate of invasive cancer of the uterine cervix, its sensitivity reduces to less than $50 \%$ when there is presence of obscuring blood, inflammation or thick areas of overlapping epithelial cells $[14,15]$. These problems with the CPS, gave rise to the advanced technologies, like, Thin Prep and Sure Path commonly used in the setup of developed countries, like UK and USA $[15,16]$. Use of these technologies however are quite resource intensive and therefore not feasible in the setup of developing countries.

On the other hand, Manual Liquid Based Cytology (MLBC) is a technique that enables cells to be suspended in a monolayer and thus improves detection of precursor lesions and improvement of specimen adequacy. MLBC has been reported to improve the effectiveness of cervical cancer screening in a population by increasing the detection of histologically confirmed neoplastic and preneoplastic disease while simultaneously decreasing over diagnosis of benign processes [17]. Also, in case of MLBC, the residual sample can be used for other tests like detection of HPV, DNA and immunocytochemistry thereby increasing the utility of $\operatorname{MLBC}[14,15]$. 
There are studies $[15,18]$ which have dealt with liquid based cytology and have found its diagnostic accuracy comparable with conventional Pap smears. MLBC method however is specific to the laboratory, available equipments, fixatives and polymer solutions, etc. Therefore the overall aim of our study was to assess the utility of indigenous MLBC in comparison of CPS for low resource settings. Specific objectives of the study were: a) To compare the morphological view of different diagnoses according to CPS and MLBC, b) To compare the cellular and nuclear parameters according to two methods and c) To compare the validity of the two methods in terms of sensitivity and specificity.

As MLBC can be used for ancillary studies like cell block study, immunocytochemistry and HPV testing, one of the ancillary techniques which we studied is cell blocks prepared from residual tissue fluids and fine-needle aspirations which can be useful adjuncts to smears for establishing a more definitive cytopathologic diagnosis. [19, 20].

Thus, our study includes MLBC in Endometrium \&Cervix with an ancillary technique, cell block to improve the diagnostic accuracy of gynecological conditions in women.

\section{Material \& Methods}

The present study was undertaken to observe the presence of endometrial cells in cervical cytology smears using conventional Pap smears and the manual method of liquidbased cervical cytology (MLBC) in all abnormal uterine bleeding cases.

Samples were collected using the split-smear technique from 82 patients (sample size) in the age group of 20 to 60 years attending the gynecology out-patient clinic at JSS Hospital, Mysore, prospectively from July 2012 to July 2014 for a period of two years.

All the patients were clinically examined in detail according to the proforma and relevant radiological findings were collected. Material collected was stained by Pap stain.

Ayre's plastic spatula was used to scrape the cervix. It was immediately put into a vial containing the fixative solution. The fixative contained $0.5 \mathrm{gm}$ of sodium chloride, $0.5 \mathrm{gm}$ of sodium citrate, $50 \mathrm{ml}$ of $10 \%$ formalin and $50 \mathrm{ml}$ of isopropyl alcohol in $100 \mathrm{ml}$. The sample was collected and mixed with equal parts of fixative. It was centrifuged at $2000 \mathrm{rpm}$ for 5 minutes. The supernatant was decanted and excess fixative was blotted 1-2 $\mathrm{ml}$ of polymer solution (containing $2 \mathrm{gm}$ of agarose, $10 \mathrm{ml}$ of polyethylene glycol, $2 \mathrm{ml}$ of poly-L-lysine and $88 \mathrm{ml}$ of distilled water) was added to the deposit. It was again centrifuged at $2000 \mathrm{rpm}$ for 5 minutes. The deposit was pipetted in a circular motion on to a glass slide. The slides were placed on a metal tray and dried in an hot air oven at 50 degrees (Indirect heat fixation) and further fixed by dipping in $95 \%$ alcohol for 5 minutes. Stained with the Conventional Pap stain.

Simultaneously, scrape smears were also collected using Ayre's spatula. The scrapings were evenly spread onto a glass slide, and immediately fixed in ethyl-alcohol fixative $(95 \%$ ethylalcohol). After fixation, smears were stained using conventional Pap stain.

Both smears were screened and results were compared. Cyto-histologic correlation was done. The Bethesda system 2001 was used for reporting cervical cytology for both groups.

The cases in which a D\&C or hysterectomy was done, specimens were collected in $10 \%$ formalin and allowed to fix overnight. Detailed gross examination was done and bits were given. Paraffin embedded $\mathrm{H}$ and $\mathrm{E}$ stained sections were obtained and studied under light microscopy.

Similarly another study on cervical pathology was conducted Samples were collected using the split-smear technique from 100 patients (sample size) in the age group of 20 to 80 years attending the gynaecology out-patient clinic at JSS Hospital, Mysore. All the patients were clinically examined in detail according to the proforma and details of other relevant laboratory investigations were collected only if necessary. Material collected was stained by Pap stain. The cases collected were patients with clinical suspicion of cervical pathology.

The processing of the samples was done as in the study on Endometrial pathology. Both smears were screened and results were compared. Cyto-histologic correlation was done in those cases in which a colposcopic biopsy was also done. The Bethesda system 2001 was used for reporting cervical cytology for both groups.

Whenever possible, ancillary techniques were applied for preparations of cell blocks and HPV- DNA testing from the residual cytocentrifuged sample.

The cases in which a colposcopic biopsy or hysterectomy was done, specimens were collected in $10 \%$ formalin and allowed to fix overnight. Detailed gross examination was done and bits were given. Paraffin embedded $\mathrm{H}$ and $\mathrm{E}$ stained sections were obtained and studied under light microscopy.

To extend our work on ancillary techniques we took the study further, to work on cell block as ancillary technique with IHC on cell blocks whenever necessary. The cell blocks studied were lesser than the liquid based cytology cases.

The study was undertaken to prepare the cell blocks from samples of manual liquid based cytology (MLBC) and to compare it with conventional pap smears and liquid based smears and correlate with histopathology wherever possible.

Samples of MLBC of which cell block preparation was made were collected from about 60 patients in the age group of 20 to 70 years with gynecological complaints like white discharge $\mathrm{P} / \mathrm{V}$ and bleeding $\mathrm{P} / \mathrm{V}$ attending the Gynecology out-patient clinic at JSS Hospital, Mysore. In the present study KI 67 and p16 markers were done on cell block preparation.

\section{Results}

In the present study, 82 cervical smears prepared by conventional pap and MLBC were studied, out of which 52 cases $(63.4 \%)$ were reported with the presence of endometrial cells, Among the 52 cases 38 cases were identified as benign 
endometrial cells and 14 cases as atypical/ malignant endometrial cells.

\subsection{Conventional Pap Smears vs Manual Liquid Based Cytology}

Among the 52 cases with endometrial cells, 46 were detected in conventional Pap smear and 38 cases in Manual Liquid Based Cytology. Out of 46 cases of endometrial cells35 were benign and 11 were atypical cells in conventional pap smear, while in manual liquid based cytology 28 were benign and 10 were atypical endometrial cells out of 38 cases. (Table 1)

Table 1. Distribution of cases into benign and Atypical/malignant endometrial cells.

\begin{tabular}{lll}
\hline Lesions & No. & Percentage (\%) \\
\hline Benign endometrial cell & 28 & 53.9 \\
Atypical/malignant endometrial cells & 10 & 19.2 \\
Absent & 11 & 21.2 \\
Inadequate & 03 & 05.7 \\
Total & 52 & 100 \\
\hline
\end{tabular}

\subsection{Morphological Distribution of Histopathological Examination}

On follow up with histopathology, maximum 8 cases of leiomyoma with proliferative endometrium, followed by 6 cases of simple hyperplasia without atypia and 4 cases each of adenomyomatous polyp and endometrial carcinoma type 1 were diagnosed. There was only one case each of endometrial type 2 carcinoma and complex hyperplasia with atypia and 3 cases each of squamous cell carcinoma, endometritis and disordered proliferative endometrium. Remaining cases were 2 proliferative endometrium and 1 case of placental site trophoblastic reaction. (Table 2) FIG 3

Table 2. Morphological distribution of histopathological examination of endometrial pathology.

\begin{tabular}{lll}
\hline $\begin{array}{l}\text { Histopathological diagnosis of } \\
\text { endometrium }\end{array}$ & No. of cases & Percentage (\%) \\
\hline Proliferative phase & 02 & 5.1 \\
Endometritis & 03 & 7.7 \\
Disordered proliferative phase & 03 & 7.7 \\
Leiomyoma & 08 & 20.5 \\
Simple hyperplasia without atypia & 06 & 15.4 \\
Complex hyperplasia with atypia & 01 & 2.6 \\
Adenomyomatous polyp & 04 & 10.2 \\
Atrophic endometrium & 03 & 7.7 \\
Endometrial carcinoma type 1 & 04 & 10.2 \\
Endometrial carcinoma type 2 & 01 & 2.6 \\
Squamous cell carcinoma & 03 & 7.7 \\
Placental site reaction & 01 & 2.6 \\
Total & 39 & 100 \\
\hline
\end{tabular}
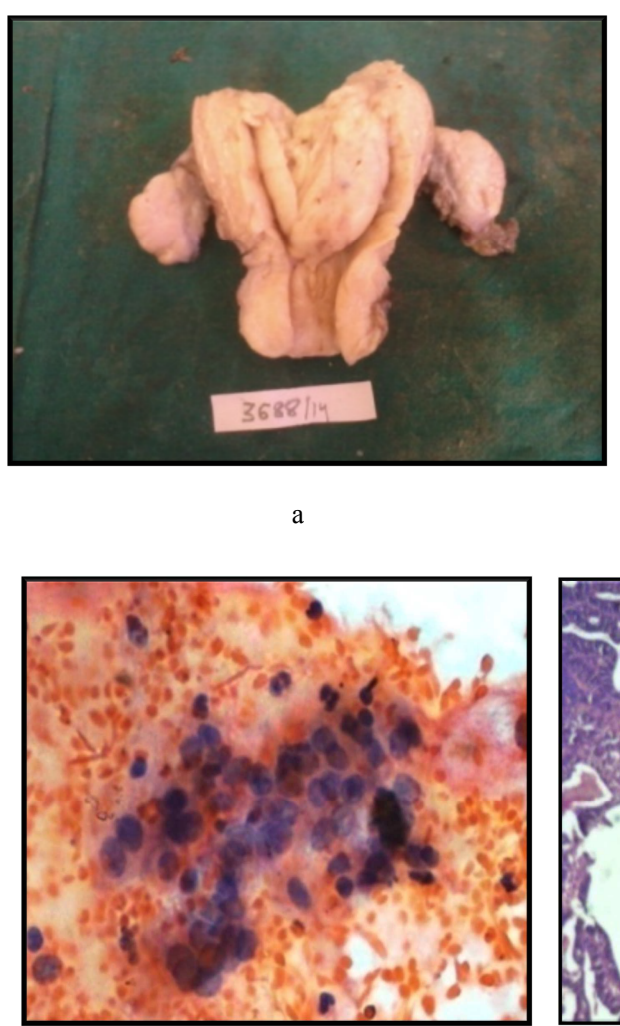
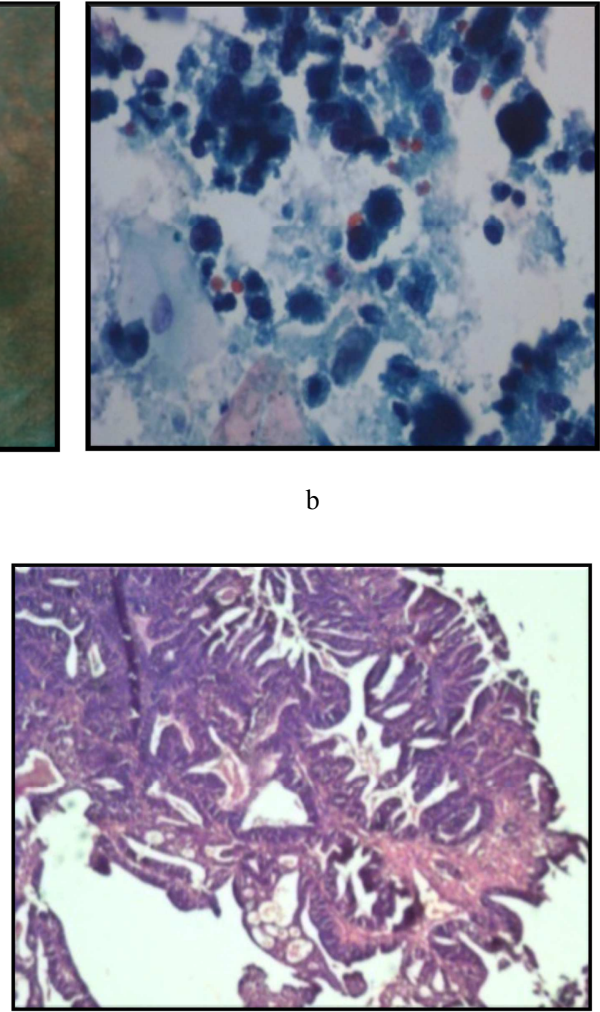

d

Fig. 3. a. Proliferative growth occupying the entire uterine cavity b. CPS-Atypical Endometrial Cells - Smear shows cells with high N/C ratio arranged in clusters with enlarged hyperchromatic nuclei and fairly abundant cytoplasm. (Pap, X400) c. MLBC Atypical Endometrial Cell - Smear shows cells with high $N / C$ ratio arranged in clusters with enlarged hyperchromatic nuclei and fairly abundant cytoplasm(Pap, X400) d. HPE - Endometrial Adenocarcinoma type 1 -Section shows a tumor displaying features of endometrial adenocarcinoma. ( $H \& E, X 10)$. 


\subsection{Conventional Pap Smear Findings in Correlation with Histopathology}

- Histopathological study was obtained in 29 out of 35 cases with benign endometrial cells and 8 out of 11 cases with atypical/malignant endometrial cells.

- Among them, 21 cases and 6 cases were consistent with histopathological findings of benign and malignant endometrial pathology respectively.

\subsection{Manual Liquid Based Cytology Findings in Histopathology Correlation}

- Histopathological study was obtained in all the 29 cases with benign endometrial cells and 8 out of 10 cases with atypical/malignant endometrial cells.

- Among them, 20cases and 6 cases were consistent with histopathological findings of benign and malignant endometrial pathology respectively

- MLBC is more sensitive and specific than CPS in diagnosis of malignant lesions.

- The contingency coefficient by LBC/Histopathology $\mathrm{V} / \mathrm{s} \mathrm{CPS} /$ Histopathology was $0.572 \mathrm{~V} / \mathrm{s} 0.556$.

Results of study of CPS vs MLBC for cervical cancer screening showed the following,

Panel of various cellular and nuclear parameters were compared between CPS and MLBC (Table 3).
Table 3. Morphological Features as Observed Through Conventional Pap Smear (CPS) and Manual Liquid Based Cytology (MLBC) Methods.

\begin{tabular}{lll}
\hline Morphological feature & CPS & MLBC \\
\hline Cellularity & Unsatisfactory in 10 cases & Adequate \\
Cleanliness of background & Absent & Absent \\
Uniformity of distribution & present & Absent \\
Artifacts & present & Rare \\
Cellular overlapping & Yes (Marked) & Yes (Rare) \\
Architectural change & Yes & Rare \\
Cellular morphological & Change yes & No \\
Nuclear change & Not always clear & $\begin{array}{l}\text { Always very } \\
\text { clear }\end{array}$ \\
\hline
\end{tabular}

Cellularity was adequate in all of the MLBC cases whereas it was unsatisfactory in many CPS cases. The background was observed to be clean in all cases of MLBC which was not the case in majority of CPS. Uniform distribution seen in MLBC with cellular overlapping was seen more in CPS than in MLBC. Artifacts were present in most CPS samples. Architectural and cellular morphologic changes were present in most of CPS samples. Inflammatory infiltrate were prominently present in CPS but decreased in MLBC cases. Nuclear changes were very clear by MLBC, but not so clear by CPS. Diagnostic features of 100 cases according to both CPS and MLBC were divided into 10 categories. FIG $4 \& 5$

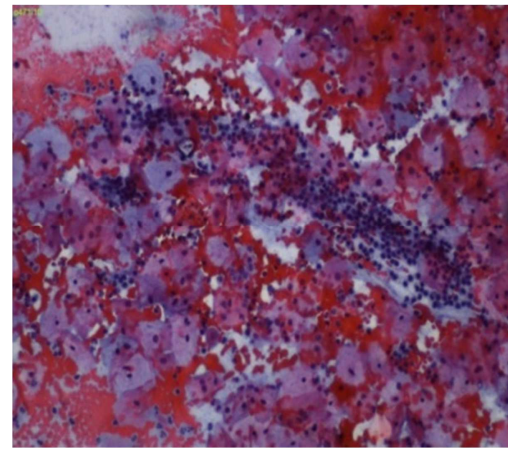

a

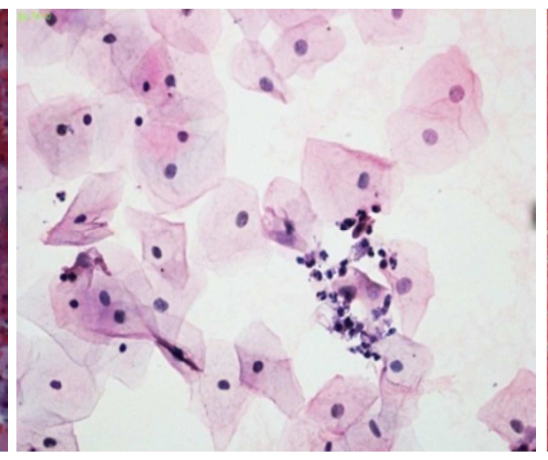

b

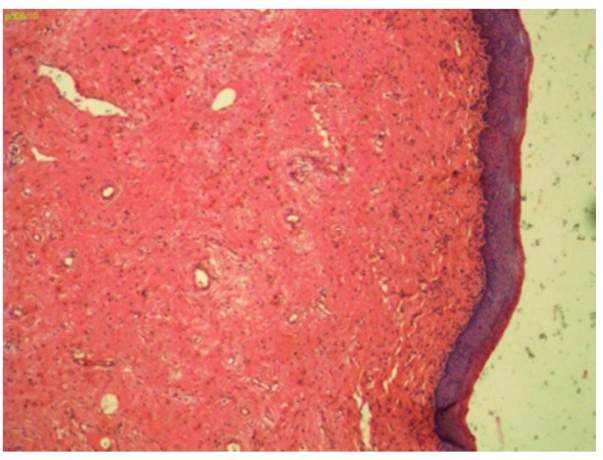

$\mathrm{c}$

Fig. 4. a. CPS-Inflammatory smear (NILM) (PAP, X200) b. MLBC-Inflammatory smear with clear background (PAP, X200) c. HPE-section studied shows chronic cervicitis. (H\&E, X200).

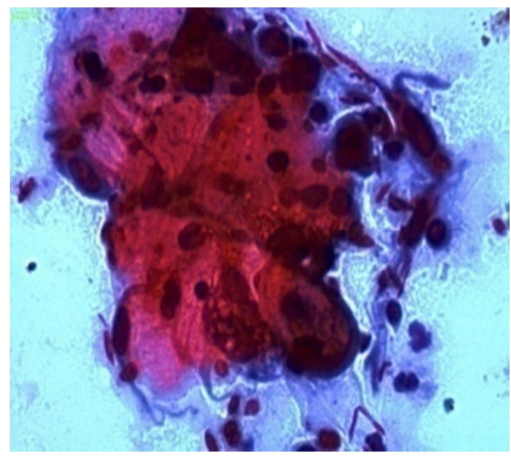

a

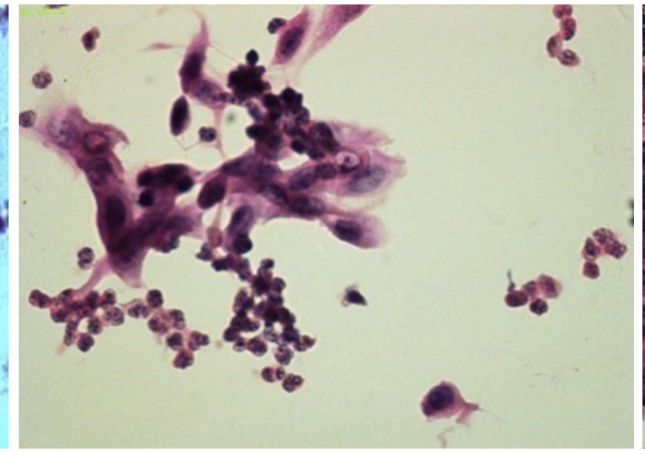

$\mathrm{b}$

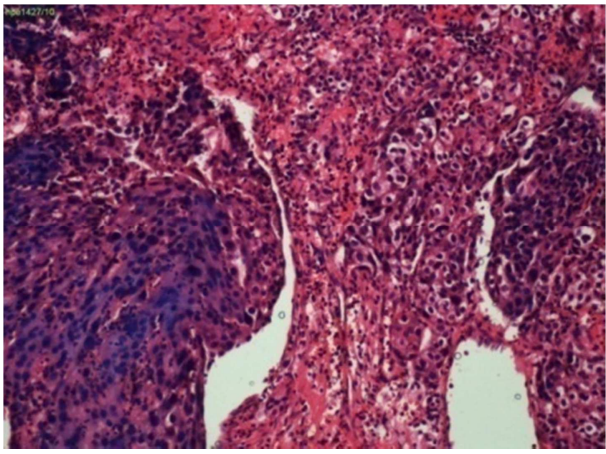

Fig. 5. a. CPS-squamous cell carcinoma of cervix (PAP, X200) b. MLBC-Squamous cell carcinoma of cervix. with clear background. (PAP, X200). c. HPEsquamous cell carcinoma of cervical biopsy. (PAP, X200). 
In the study, the comparison between conventional CPS and MLBC showed certain observations in different diagnostic categories. Both the methods showed same number of normal smears. Inflammatory smears diagnosis was more by CPS than by MLBC ( $42 \%)$. However, diagnosis of Bacterial Vaginosis (14\%) and low grade squamous intraepithelial lesion (36\%) were more by MLBC which is a significant observation. Also the number of infestations detected by MLBC method was increased koilocytic atypia, candidiasis and leptothrix. Cytohistological correlation was done in 22 cases. Increased detection rate was $150 \%$ for low grade intraepithelial lesion. The rate of concordance with histology was $77 \%$ for CPS and LBC, whereas, it was $86 \%$ for MLBC. The rate of increased detection of LSIL through MLBC was $150 \%$. (Table 4 )

Table 4. Comparison of Classification of Cases by Conventional Pap Smear (CPS) and Manual Liquid Based Cytology (MLBC) with that by HistoPathological Examination (HPE).

\begin{tabular}{llll}
\hline Categories & CPS & MLBC & HPE \\
\hline Normal smear & 14 & 15 & 1 \\
Inflammatory Smear (NILM) & 42 & 20 & 8 \\
Bacterial Vaginosis & 7 & 14 & 0 \\
LSIL & 14 & 36 & 8 \\
HSIL & 1 & 1 & 1 \\
Squamous cell carcinoma & 2 & 2 & 1 \\
Adenocarcinoma & 1 & 1 & 1 \\
Menopausal & 8 & 6 & 1 \\
Unsatisfactory & 9 & 1 & 0 \\
Infestations & & & \\
HPV (Koilocyticstypia) & 2 & 3 & 1 \\
Candidiasis & 0 & 1 & 0 \\
Leptothrix & 0 & 3 & 0 \\
Total & 100 & 100 & 22 \\
\hline
\end{tabular}

In addition, to compare the validity of the two methods, we estimated sensitivity and specificity of the two considering HPE as the gold standard for the two important diagnoses, namely, LSIL and inflammation. In the diagnosis of LSIL, MLBC was more sensitive than CPS (75\% vs. $50 \%)$ with similar specificity $(100 \%)$. In case of inflammation also, MLBC was found to perform better being more specific (92\% vs. $77 \%$ ) with same sensitivity (89\%).

To work on the utility of MLBC on ancillary studies a further study was done between 2011 to 2013. Of 60 cases in our study, 10 cases had no deposit and cell block diagnosis could not be offered. This inadequate material may be due to sampling errors. Of the rest 50 cases with adequate material 7 were neoplastic and 43 were non- neoplastic.

43 non-neoplastic lesions include chronic polypoidal endocervicitis (CPEC - 10 cases), Koilocytes (3 cases), chronic cervicitis (12 cases), normal study (10 cases), acute on chronic cervicitis (7 cases), only hemorrhage (1 case).

Neoplastic lesions included squamous cell carcinoma SCC ( 1 case), dysplasia ( 2 cases), carcinoma in situ (4 cases)

10 cases of the cell blocks had no deposits. Of these only 3 cases were reported as satisfactory on conventional smears and 7 cases were unsatisfactory on conventional smears and had inadequte samples for MLBC smear.This shows that adequte sampling procedure plays a major role for the better results by cell blocks. (Table 5)

Table 5. Morphological distribution of cases diagnosed on cell block.

\begin{tabular}{llll}
\hline SI.NO & Cell block diagnosis & No of cases & percentage(\%) \\
\hline 1 & SCC & 1 & 1.7 \\
2 & CIN 3 & 1 & 1.7 \\
3 & CIN 2 & 2 & 3.3 \\
4 & CIN 1 & 1 & 1.7 \\
5 & Dysplasia & 2 & 3.3 \\
6 & Chronic cervicitis(CC) & 12 & 20 \\
7 & CPEC & 10 & 16.7 \\
10 & Normal study & 10 & 16.7 \\
8 & Acute on chronic & 7 & 11.7 \\
9 & cervicitis(ACC) & 3 & 5 \\
10 & Koilocytes & 1 & 1.7 \\
11 & Only hemorrhage & 10 & 16.7 \\
12 & No deposit & 60 & 100 \\
\hline
\end{tabular}

Cases reported as No deposits were maximum when MLBC had inadequate material and were minimum when LBC smears were not done and sediment was directly processed for cell blocks.

\subsection{Comparison of Neoplastic Lesions Diagnosed on Cell Blocks with CPS and MLBC}

7 cases of cell blocks were diagnosed as neoplastic including carcinoma in situ. They included squamous cell carcinoma SCC (1 case), dysplasia ( 2 cases), carcinoma in situ (CIN) (4 cases). SCC was diagnosed as HSIL in CPS and LBC. 1 case of dysplasia was diagnosed as inflammatory on CPS and MLBC and other case of dysplasia was diagnosed as HSIL on CPS and MLBC. 1 case of CIN was unsatisfactory on CPS and 3 cases of CIN were diagnosed as HSIL and LSIL.

This shows that cellular architecture is better preserved and neoplastic lesions which are underdiagnosed on CPS and MLBC can be correctly diagnosed on cell blocks.

\subsection{Comparison of Cell Block Diagnosis with Histopathology}

Histopathologic correlation was obtained in 19 cases, of these 4 cases were neoplastic and 15 cases were non neoplastic. Of 19 cases, cell block diagnosis correlated with histopathology in 14 cases. (Table 6)

Table 6. Histopathological correlation of cell blocks and CPS

\begin{tabular}{llll}
\hline SL NO. & Histopathological Correlation & Cell blocks & CPS \\
\hline 1 & Yes & $14(74 \%)$ & $10(53 \%)$ \\
2 & No & $5(26 \%)$ & $9(47 \%)$ \\
3 & Total & $19(100 \%)$ & $19(100 \%)$ \\
\hline
\end{tabular}




\subsection{Statistical Analysis}

Sensitivity and specificity of conventional smears, LBC smears and cell blocks were calculated and compared.

- Positive predictive value for diagnosing neoplastic lesions on cell blocks: $75 \%$

- Efficacy of cell blocks in the diagnosis of neoplastic lesions: $89 \%$

- Concordance Rate of CB/Histopathology Vs CPS/Histopathology is $74 \%$ vs $54 \%$.

\section{Discussion}

Although cervical cancer was historically commoner than EC, cytological screening has progressively decreased its prevalence. On the contrary, EC shows an increasing trend. In developed countries, where cervical cancer screening is performed, it is estimated that the number of women who die from EC is almost two fold higher than the number of women who die from cervical cancer [21]. Unfortunately, although screening strategies for cervical cancer continue to improve, screening for EC with cytological techniques remains widely unaccepted by the medical community.

82 cases with abnormal bleeding history were sampled and smears obtained in the above mentioned way. These 82 cases of MLBC were also prepared and compared with the corresponding conventional pap smears. Cytology smear results for the 52 patients out of 82 cases showed endometrial cells. Among 52 cases, histopathological correlation was obtained in 39 cases.

More recent abstracts reported endometrial cells of $1.8 \%$ and $0.5 \%$ on Pap tests in women 40 years and older [22, 23]. Though many of these women with endometrial cells on Pap tests $(61 \%)$ had their Pap test collected in the first 14 days of the menstrual cycle [22].

- However, the various studies published since 1970 shows were listed below- (Table-7)

Table 7. Pap smear studies published since 1970 in women with endometrial malignancies (35).

\begin{tabular}{llllll}
\hline Study & year & $\begin{array}{l}\text { Total } \\
\text { no. }\end{array}$ & $\begin{array}{l}\text { Normal } \\
\text { results }\end{array}$ & $\begin{array}{l}\text { Abnormal } \\
\text { results }\end{array}$ & BEC \\
\hline Burk et al"[24]". & 1974 & 154 & 123 & 31 & unknown \\
Vuopala et al"[25]" & 1977 & 88 & 9 & 79 & abnormal \\
Bibbo et al"[26]" & 1979 & 33 & 10 & 23 & normal \\
Lozowski et al"[27]" & 1986 & 58 & 23 & 35 & abnormal \\
Kuebler et al"[28]" & 1989 & 34 & 12 & 22 & Unknown \\
Larson et al"[29]" & 164 & 94 & 94 & 70 & Normal \\
Zuna and Erroll et al"[30]" & 1996 & 61 & 25 & 36 & unknown \\
Eddy et al"[31]" & 1997 & 112 & 59 & 53 & Abnormal \\
Fukuda et al"[32]" & 1999 & 99 & 68 & 31 & Normal \\
Gu et al."[33]" & 2001 & 76 & 34 & 42 & unknown \\
Morimura et al"[34]" & 2002 & 53 & 15 & 38 & normal \\
DuBeshter et al."[35]" & 2003 & 300 & 109 & 191 & abnormal \\
Brown et al."36]" & 2005 & 412 & 139 & 273 & Abnormal \\
Thrall et al."[37]" & 2007 & 73 & 41 & 32 & abnormal \\
Present study & 2012 & 52 & 38 & 14 & abnormal \\
\hline
\end{tabular}

- The reported prevalence of normal endometrial cells in all smears varied between $0.1 \%$ to $1.4 \%$ [38] and Atypical glandular cells ranging from 0.18 to $0.74 \%$ [39], [40]

- The increased prevalence of endometrial cells in our study may be because of confinement of patients selection was only from bleeding history cases in which some pathology must be there.

The presence of endometrial glandular cells was found to indicate a five times greater risk of endometrial disease [41].

However, evaluation of prevalence of endometrial pathology might be complicated because of selection bias and no adequate control for comparison.

Previous studies showed Endometrial cells on Pap tests have been associated with normal endometrial findings in 22$97 \%$ of women, polyps in $1-41 \%$, hyperplasias $1-20 \%$, atypical hyperplasia in $0.6-8 \%$, and carcinoma in $1-15 \%$ [42, $43,44]$.

In our study, we had maximum of cases with leiomyoma with proliferative endometrium in $8(20.5 \%)$ cases, followed by endometrial hyperplasia without atypia in 6 (15.4\%) cases, adenomyomatous polyps in $4(10.3 \%)$ cases and proliferative endometrium, disordered proliferative endometrium and endometritis in $3(7.7 \%)$ cases each.

There were $8(20.5 \%)$ cases of malignancy, and $1(2.6 \%)$ case of precursor lesion with complex hyperplasia with atypia. So, the final diagnosis was completely benign pathology in 31 patients and carcinoma in 8 patients.

Among all benign lesions, leiomyoma with proliferative endometrium was most common because, leiomyoma is found to be the most common pathology associated with abnormal uterine bleeding by causing inadequate contraction of myometrium and irregular spotting leads to shedding of endometrium.

Recently, Obenson and coworker reported that their most common benign lesions were endometrial polyps [45]. While in our study, adenomyomatous polyp was third most common lesion preceded by simple hyperplasia.

Sensitivity of Pap testing for true glandular neoplasia is less than that for squamous lesions, in part because glandular lesions arise in the endocervical canal and endometrial cavity where they may be difficult to sample.

The low sensitivity for endometrial malignancy was improved only marginally (from $38.3 \%$ to $43.8 \%$ ) by the addition of the 2001 Bethesda System reporting category of benign endometrial cells in women aged $>40$ years, but specificity of the Pap test for the diagnosis of endometrial hyperplasia or malignancy decreases from $99.8 \%$ to $96 \%$ [31].

Available literature suggested compared with conventional cytology, LBC may be associated with a higher prevalence of NECs because of more consistent use of sampling instruments for LBC with better access to this area [23].

The ThinPrep Pap test has high sensitivity and specificity in detecting or suggesting the presence of endometrial cancer. Certain cytomorphologic features are helpful in distinguishing benign and malignant endometrial lesions [32].

Schorge et al., using ThinPrep, demonstrated a sensitivity 
of $65.2 \%$ among 45 patients with endometrial cancer [33].

In our study we also found that the MLBC method was comparable to the CPS. Though the number of inadequate specimen for MLBC was 5 whereas 1 for conventional pap smear, the sensitivity, specificity, negative and positive predictive value was better for MLBCs. Even on cross tabulation, MLBC showed better histopathological correlation than conventional pap smear.

MLBC showed a slightly higher concordance coefficient (0.572) than CPS (0.556)

The advantages of MLBC are increased detection of cellular abnormalities. This is because of many factors like adequacy of sample, type of spatula used to collect the sample, type of sampling like whether direct to vial or split sample method. Also the polymer solution which is prepared in our laboratory contains agarose, polyethylene glycol, alcohol and poly-L-lysine, form a thin monolayer of cells within a clean background $[15,18]$.

This helps to detect nuclear changes in readable clean background MLBC method which we follow helps to bring in a cheap method. In addition the residual specimen can be used for ancillary testing like immunocytochemistry (IHC) on cell block and detection of HPV DNS by PCR or insitu hybridization $[15,1]$.

IHC markers which can be studied are p16inK4a, MIB-1, BD-ProExC and L1 [48].

To continue with the study of advantages of MLBC we took up a study on cell block and immunocytochemistry on cell block between the periods of 2011 to 2013 .

Cell blocks can be prepared from all types of cytological specimens, except preparations with low cellularity such as cerebrospinal fluids. There are several techniques to produce cell blocks, such as cytocentrifugation, either with direct formalin fixation or fixation after addition of plasmathromboplastin [49].

In addition, there are commercially available systems, such as the 'Shandon Cell block Preparations System', which offers a standardized technique with a high reproducibility. Cell blocks perform in a highly reproducible way when stained with most antibodies, except for some used in the work- up of lymphoid lesions. One distinct advantage of cell blocks is that many slides can be prepared for extensive panels of immunostains. In addition, the quality control of cell block staining is identical to that of histopathology. The morphology of cell blocks is identical to that seen in histological specimens and therefore familiar to most pathologists [50].

\section{Uses of Cell Block Are}

1. It improves the diagnosis of malignant conditions of cervix due to better presentation of cytomorphologic features, better staining characteristics of the nucleus, nucleoli and cytoplasm, clear recognition of nuclear and cytoplasmic features $[51,52]$ (Table 8 )
Table 8. Sensitivity and specificity of cell blocks in diagnosing neoplastic lesions of cervix.

\begin{tabular}{lll}
\hline Authors & Sensitivity (\%) & Specificity (\%) \\
\hline Gangane Net al(2007)"[53]" & 86.3 & 100 \\
Gupta.S et al(2007)"[54]" & 87.5 & 100 \\
Catteau X (2012)"[55]" & 50 & 100 \\
Present study & 75 & 93 \\
\hline
\end{tabular}

2. Thus, if used in adjunct of the smear it aids in providing a reliable diagnosis of cervical cancer in majority of clinically suspected cases and thus the biopsy need can be reduced significantly in resource poor settings [54]

- we also found also similar advantages in our study which were observed by Wei Q et al [56] who like us also found that cell block increased both sensitivity and specificity.

3. Cell block can be used to do IHC on suspicious cases which were done in our study. Stains used were p16inK4A and KI67. It was found that both markers increased their expression as the grade of dysplasia increased and maximum in cervical cancer. Thus helping in improving diagnostic accuracy of cervical lesion. These were consistent with findings of Siddham V. B et al [57] for p16inK4a and by Sahebali s et al [58] for KI67.(Table 9,) FIG 6

There are many studies done on markers and endometrium. Ghosh et al have found that there was increased expression of Cyclin D1 and Ki-67 in patients with endometrial carcinoma relative to proliferative endometrium and simple hyperplasia, but there was no such difference between cases of atypical hyperplasia and endometrial carcinoma. Cyclin D1 expression had a positive correlation with Ki-67 expression. Cyclin D1 together with Ki-67 may be a marker for endometrial carcinogenesis and tumor cell proliferation [59].

Other marker studies on cervix have been undertaken p16 and Survivin expression can be correlated with the clinicopathological and prognosis of cervical cancer. p16 protein is found to be associated with CIN grade and lymph node metastasis. Survivin protein also is the same. Both together were positively correlated with cervical cancer $(\mathrm{r}=0.854$, $\mathrm{p}, 0.001)$ and associated with poor prognosis of cervical cancer [60].

Table 9. Table showing the different categories of cervical lesions and markers.

\begin{tabular}{lllll}
\hline Categories of lesions & $\begin{array}{l}\text { Number of } \\
\text { lesions(60) }\end{array}$ & P-16 & Ki-67 & Ecadherin \\
\hline Squamous cell carcinoma & 2 & ++ & ++ & - \\
Dysplasia & 21 & + & + & - \\
Inflammatory conditions & 20 & - & - & + \\
Normal smears(NILM) & 17 & - & - & ++ \\
\hline
\end{tabular}



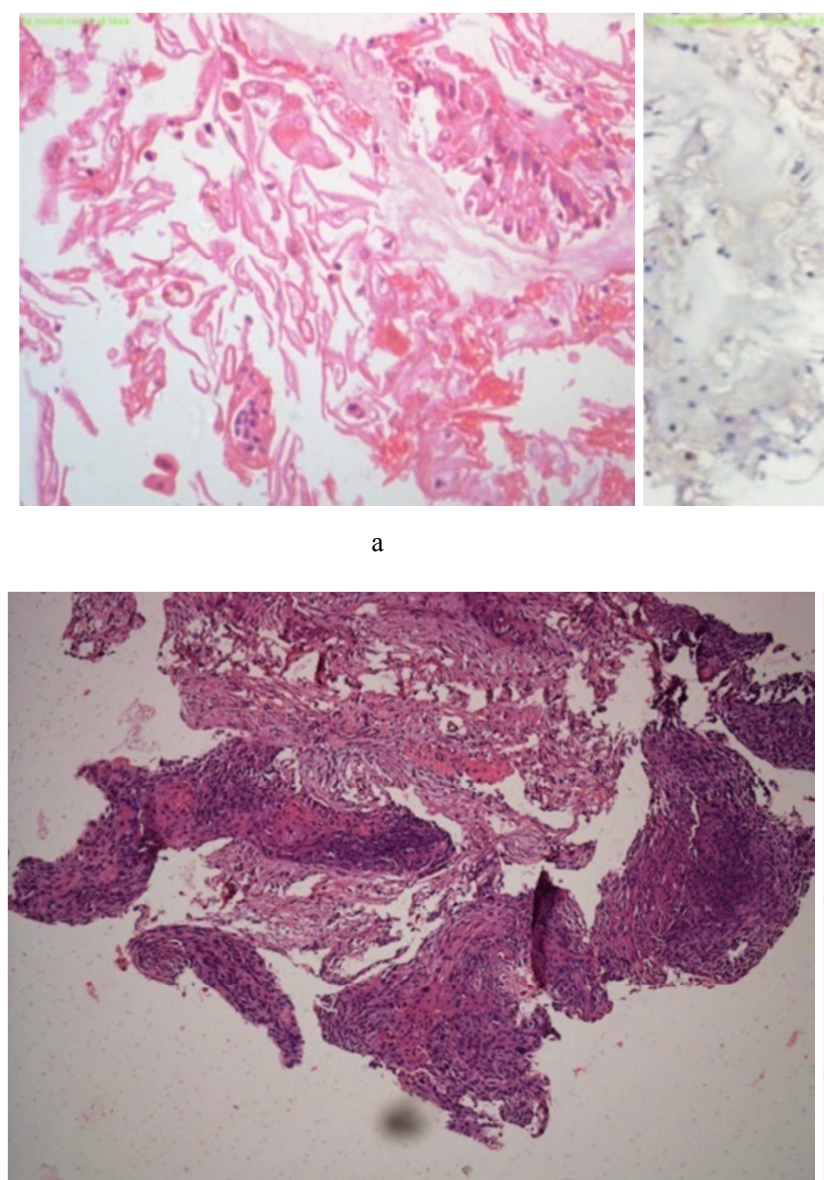

c
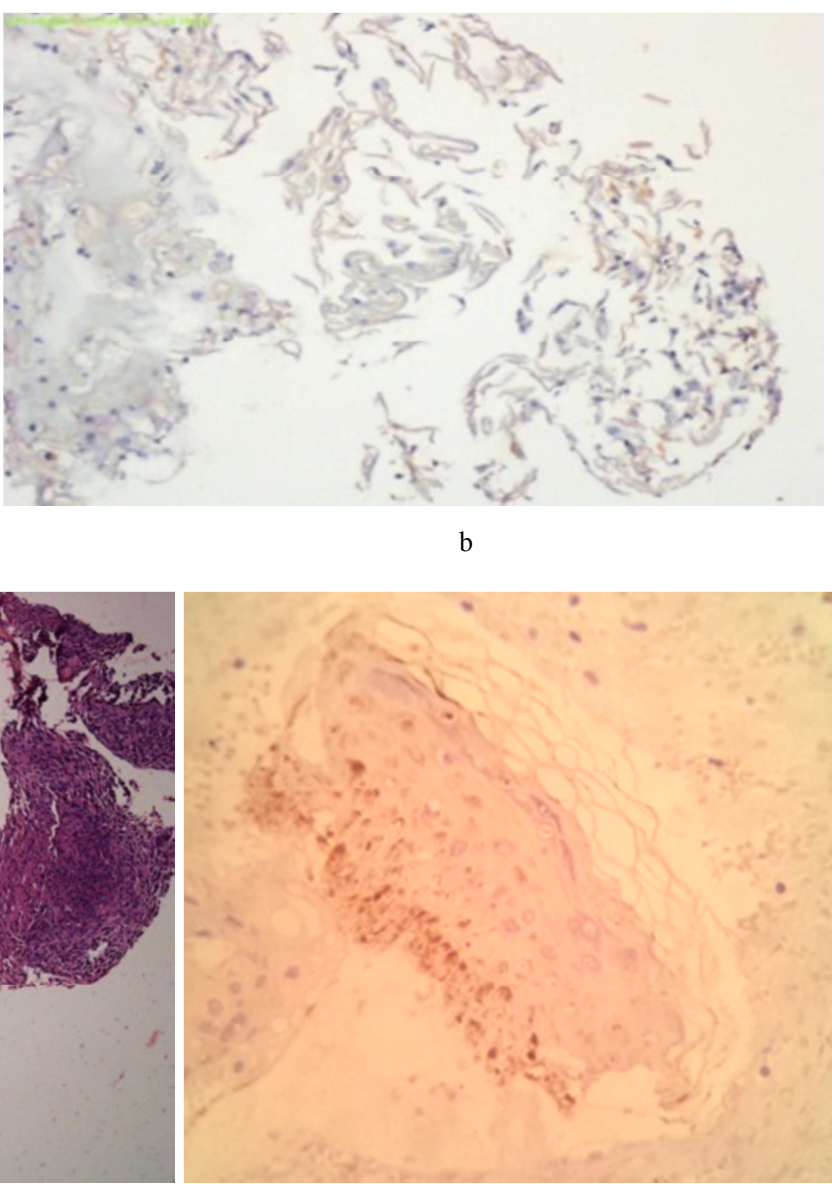

d

Fig. 6. a. cell block of normal cervix. (H\&E, x200) b. p16 ink4a negative on cell block of normal cervix (x200) c. cell block of cervix-HSIL (H\&E, X200) d. pl6ink4a positive on cell block of HSIL (H\&E, X200).

\section{Conclusion}

Women are vulnerable group to many illnesses. Gynecological pathology with conditions related to Endometrium and cervix are major causes of the health problems ranging from infections to neoplasia which require early detection and treatment.

The commonly used method of conventional Pap smear (CPS) which was used as an screening method has its limitations. It has many obscuring factors like blood and inflammatory cells which limited the sensitivity and specificity of the test.

Liquid based cytology (LBC), a methodology was introduced in the advanced countries to overcome these limitations by making a thin monolayer of cells with a clear background. This method but is costly for developing countries where awareness, sources for health care are scarce. To obviate this, a Manual Liquid based cytology method (MLBC) was introduced in our setup.

It has been found to be useful in both Endometrial and cervical cytology in increasing the detection of infection and neoplastic conditions of female genital tract. It is also a cost effective method which can be used to test ancillary techniques of MLBC like cell block study, immunocyto chemistry and HPV testing.

\section{References}

[1] Amant F, Moerman P, Neven P et al, Endometrial cancer, Lancet: 366: 491-505. 2005.

[2] Sorosky J I Endometrial cancer, Obstet Gynecol; 120: 383-97. 2012.

[3] Bakkum Gamez J.N, Gonqalez Bosquet J Laack N.N, Mariani A, Dowdy SC, Current issues the management of endometrial cancer, Mayo clin Proc: 83; 97-112. 2008.

[4] Cancer Research UK, Available at: www. Cancer research chuk. or/cancer info/cancer stats/types/uterus /incidence /\#geog.

[5] Howlader N, Noone AM, Kracho M et al. eds. SEER Cancer Statistics Review, 1975-2008. Bethesda, MD; National Cancer Institute; 2011.

[6] Ushikima K, Current status of gynecological cancer in Japan. J Gynaec Oncol 20: 67-71. 2009. 
[7] Oncology Committee. Annual report on cervical endometrial, and ovarin cancer. Acta Obstet Gynaecol Jpn; 61: 913-95; 2007.

[8] Linkov F, Edvards R, Balk J et al. Endometrial hyperplasia, endometrial cancer and prevention: gaps in existing research of modifiable risk factors. Eur J Cancer; 44: 1632-44; 2008.

[9] Kaaks R, Lukanova A, Kurzer M S Obesity, endogenous hormones, and endometrial cancer risk: a synthetic review. Cancer Epidemic biomarkers Prev; 11: 1531-43, 2002.

[10] Calle EE, Rodriguez C. Walkar-Thurmond K, Thun MJ Overweight, obesity, and mortality from cancer in prospectively studied cohort of U.S adults. N Engl J Med; 348: 1625-38; 2003.

[11] Anderson GL, Judd HL, Kaunitz AM et al Women's health Initiative Investigators. Effects of estrogen plus rogestin on gynecologic cancers and associated diagnostic procedures: The Women's health Initiative randomized trial. JAMA. 290: 1739-48; 2003.

[12] Ferlay J, Soerjomataram I, Ervik M, Dikshit R, Eser S, Mathers C, Rebelo M, Parkin DM, Forman D, Bray, F. GLOBOCAN 2012 v1.0, Cancer Incidence and Mortality Worldwide: IARC Cancer Base No. 11 [Internet]. Lyon, France: International Agency for Research on Cancer. Available from http://globocan.iarc.fr. 2013.

[13] NCRP. Consolidated report of population based cancer registries 2001-2004, Indian Council of Medical Research, New Delhi, India; 2006.

[14] Sherwani RK, Khan T, Aktar K, et al. Conventional pap smear and liquid based cytology for cervical cancer screening-A comparative study. J Cytology, 24, 167-72; 2007.

[15] Kavatkar AN, Nagwamshi CA, Dabaks M. Study of a manual method of liquid based cervical cytology. Indian J Pathology and Microbiology, 59, 190-4; 2008.

[16] Deshou H, Changhua W, Quiyan L, et al. Clinical utility of LiquiPrep cytology system for primary cervical cancer screening in a large urban hospital setting in China. J Cytology, 26, 20-5.; 2009.

[17] Baker JJ). Conventional and liquid based cervicovaginal cytology. A comparison study with clinical and histologic Follow-up. Diagn Cytopathology, 27, 185-8; 2002.

[18] Maksem JA, Finnomore M, Belsheim BL, et al Manual method for liquid based cytology. A demonstration using 1,000 Gynaecological cytologies collected directly to vial and prepared by a smear - slide technique. Diagn Cytopathology, 25, 334-8; 2001.

[19] Bibbo. M, Klump, WJ, Dececco. J, and Kovatich AJ, "procedure for Immunocytochemical Detection of P16 INK4 in Thin-Layer, Liquid-Based Specimens," actacytologica, Vol. 46, No. 1, pp (2002,). 25-29 doi: 10.1159/000326711.

[20] Luzzatto. L, van. C, Haaften. C, and Boon, M.E "proliferation Patterns of Cervical cells as visualized in Leiden Liquid cytology Slides, "Diagnostic cytopathology, 31, 5-9 doi: 10.1002/dc.2011; 2004.

[21] Jemal A, Siegel R, Ward E et al. Cancer statistics, 2007. CA Cancer J. Clin; 57: 43-66; 2007.

[22] Saad RS, Mahdavy M, Takei H, Ruiz B. Endometrial cells in cervical specimens of women 940 years of age (abstract). ActaCytol); 48: 678-9; 2004.

[23] Bean S, Connolly K, Roberson J, et al. Incidence and clinical significance of normal endometrial cells in patients 40 years and older (abstract). Acta Cytology; 48: 677; 2004.

[24] Burk JR, Lehman HF, Wolf FS. Inadequacy of Papanicolaou smears in the detection of endometrial cancer. N Engl J Med; 291: 191-92; 1974.

[25] Vuopala S. Diagnostic accuracy and clinical applicability of cytological and histological methods for investigating endometrial carcinoma. Acta Obstet Gynecol Scand 1977; 70(suppl): 1-72.

[26] Bibbo M, Reale FR, Reale JC et al, Assessment of three sampling techniques to detect endometrial cancer and its precursors. A preliminary report. Acta Cytol.; 23: 353-59; 1979.

[27] Lozowski MS, Mishriki Y, Solitare GB. Factors determining the degree of endometrial exfoliation and their diagnostic implications in endometrial adenocarcinoma. Acta Cytol; 30: 623-27; 1986.

[28] Kuebler DL, Nikrui N, Bell DA. Cytologic features of endometrial papillary serous carcinoma. Acta Cytol; 33: 120 $26 ; 1989$.

[29] Larson DM, Johnson KK, Reyes CNJr, Broste SK. Prognostic significance of malignant cervical cytology in patients with endometrial cancer. Obstet Gynecol; 84: 399-03; 1994.

[30] Zuna RE, Erroll M. Utility of the cervical cytologic smear in assessing endocervical involvement by endometrial carcinoma. Acta Cytol; 40: 878-84; 1996.

[31] Eddy GL, Wojtowycz MA, Piraino PS, Mazur MT. Papanicolaou smears by the Bethesda System in endometrial malignancy: utility and prognostic importance. Obstet Gynecol; 90: 999-3; 1997.

[32] Fukuda K, Mori M, Uchiyama M et al. Preoperative cervical cytology in endometrial carcinoma and its clinicopathologic relevance. Gynecol Oncol; 72: 273-77; 1999.

[33] Gu M, Shi W, Barakat RR, Thaler H, Saigo P. Pap Smear in Women with Endometrial Carcinoma. Acta Cytologica; 45(4): 555-60. 2001

[34] Morimura Y, Nishiyama H, Hashimoto T, et al. Diagnosing endometrial carcinoma with cervical involvement by cervical cytology. Acta Cytol; 46: 284-90; 2002.

[35] DuBeshter B, Deuel C, Gillis S, Glantz C, Angel C, Guzick D. Endometrial cancer: the potential role of cervical cytology in current surgical staging. Obstet Gynecol; 101: 445-50; 2003.

[36] Brown AK, Gillis S, Deuel C, Angel C, Glantz C, Dubeshter B. Abnormal cervical cytology: a risk factor for endometrial cancer recurrence. Int J Gynecol Cancer; 15: 517-22; 2005.

[37] Thrall M, Kjeldahl K, Gulbahce HE, Pambuccian SE. Liquidbased Papanicolaou test (Sure Path) interpretations before histologic diagnosis of endometrial hyperplasias and carcinomas. Cancer Cytopathology: 111(4):217-23; 2007.

[38] Canfell K, Kang YJ, Clements M, Moa AM, Barel V. Normal Endometrial Cells in Cervical Cytology: Systematic Review of Prevalence and Relation to Significant Endometrial Pathology. Journal of medical screening; 15 (4): 188-98; 2008. 
[39] Solomon D, Frable WJ, Vooijs GP et al. ASCUS and AGUS criteria. International Academy of Cytology Task Force summary. Diagnostic Cytology Towards the $21^{\text {st }}$ Century: An international Expert Conference and Tutorial. Acta Cytol; 42: 16-24. 1998.

[40] Wood MD, Horst JA, Bibbo M. Weeding atypical glandular cell look-alikes from the true atypical lesions in liquid- based Pap tests: a review. Diagn Cytopathol; 35: 12-17; 2007.

[41] Chang A, Sandweiss L, Rose S. Cytologically benign endometrial cells in the Papanicoulaou smears of postmenopausl women. Gynecol Oncol; 80: 37-43; 2001.

[42] Mount SL, Wegner EK, Eltabbakh GH, Olmsted JI, Drejet AE. Significant increase of benign endometrial cells on Papanicolaou smears in women using hormone replacement therapy. Obstet Gynecol; 100: 445-50; 2002.

[43] Cherkis RC, Ptten SF, Andrews TJ, Dickinson JC, Patten FW. Significance of normal endometrial cells detected by cervical cytology. Obstet Gynecol; 71: 242-4; 1988.

[44] Montz FJ. Significance of 'normal endometrial cells in cervical cytology from asymptomatic postmenopausal women receiving hormone replacement therapy. Gynecol Oncol; 81: 33-9; 2001.

[45] Obenson K, Abreo F, Grafton WD. Cytohistologic correlation between AGUS and biopsy-detected lesions in postmenopausal women. Acta Cytol; 44: 41-45; 2000.

[46] Zhou J., Joseph F. Tomashefski, Jr, Khiyami A. ThinPrep Pap Tests in Patients With Endometrial Cancer: A Histo Cytological Correlation Diagnostic Cytopathology; 35: 448$53 ; 2007$.

[47] Koss LG, Durfee GR. Cytologic diagnosis of endometrial carcinoma. Result of ten years of experience. Acta Cytol; 6: 519-31; 1962.

[48] Pinto A P, Degen M, Villa L L, Cibas E S. Immunomarkers in gynaecologic cytology the search for the ideal biomolecular papanicolaou test. Acta Cytol, 56, 109-21; 2012.

[49] Fetsh P, Simisir A, abati A. comparison of three commonly used cytology preparations in effusion immunocytochemistry; 26: 61-7, 2002.

[50] Skoog L, Tani E. immunocytochemistry: an indispensable technique in routine cytology. cytopathology, 22, 215-229, 2011.
[51] Nathan N A, Narayan E, Mary M, Horn M J. Cell block cytology. Improved Preparation and Its Efficacy in Diagnostic Cytology Am J Clin Pathol 114: 599-606; 2000.

[52] Luis A, Diaz Rosario, Salim E, Kabawat. Cell block preparation by inverted filter sedimentation is useful in the differential diagnosis of atypical glandular cells of undetermined significance in thin prep specimens. Cancer cytopathol; 90: 265-72; 2000.

[53] Gangane N, Mukerji MS, Anshu, Sharma SM. Utility of microwave Processed cell blocks as a complement to cervicovaginal smear. Diagnostic Cytopathology. 35: 338-341; 2007.

[54] Gupta S, Halder K, Khan VA, Sodhani P. Cell block as an adjunct to conventional Papanicolaou smear for diagnosis of cervical cancer in resource-limited settings. Cytopathology. 18(5): 309-15; 2007.

[55] Catteau X, Simon P, Noël JC. Detection of High-Grade Lesions on Cell Blocks from Residual Fluids of Pap Smears Diagnosed as Low-Grade Abnormalities: A Preliminary Pilot Study. Acta Cytologica; 56: 247-250; 2012.

[56] Wei Q, Liu J, Zhang Z, Yang Q, Zhao T. Morphological features of cell blocks prepared from residual Liqui-PREP samples can distinguish between High-grade squamous intraepithelial lesions and squamous cell carcinomas. Acta Cytol. 55: 245-250; 2011.

[57] ShidhamVB, MehrotraR, Varsegi G, Amore K L, Hunt B, Narayan R.p16 ${ }^{\text {INK4a }}$ immunocytochemistry on cell blocks as an adjunct to cervical cytology: Potential reflex testing on specially prepared cell blocks from residual liquid-based cytology specimens. Cytojournal: 1-10; 2011.

[58] Maksem JA, Finnemore M, Belsheim BL, Roose EB, Makkapati SR, Eatwell L et al. Manual method for liquidbased cytology: a demonstration using 1,000 gynecological cytologies collected directly to vial and prepared by a smearslide technique. Diagn. Cytopathol. 25. 334-8; 2001. Nov.

[59] Shevra CR. Ghosh A, Kumar M. et al Department of Pathology, Institute of Medical Sciences, Banaras Hindu University, Varanasi, Uttar Pradesh, India cyclin D and $\mathrm{Ki}$ expression in normal, hyperplastic and neoplastic endometrium; 61; 15-20; 2015.

[60] Liu H.G, Wang Y H, Wang L.L, Hao M.P 16ink4A and survivin diagnostic and prognostic markers in cervical intraepithelial neoplasia and cervical sqamous cell carcinoma. exp mol pathol, 44-49, 2015. 